\title{
Recombinant Pseudomonas Vaccine: technological aspects of obtaining and evaluating quality indicators
}

\section{Natalia A. Mihailova, Alexei A. Kaloshin, Ekaterina M. Zimina, Alena V. Soldatenkova, Evgeniy O. Kalinichenko, Olga V. Borisova}

The Mechnikov Research Institute for Vaccines and Sera, Moscow, Russia
Corresponding Author: Mikhailova Natalia Alexandrovna; email: alex-k-1973@yandex.ru

Published 13 January 2022

Publishing services provided by Knowledge E

\section{(c) Mikhailova Natalia}

Alexandrovna et al. This article is distributed under the terms of the Creative Commons

Attribution License, which permits unrestricted use and redistribution provided that the original author and source are credited.

Selection and Peer-review under the responsibility of the 8 th Scientific and Practical Conference Conference Committee.

\section{G OPEN ACCESS}

\begin{abstract}
For an aim to prevent Pseudomonas aeruginosa, a candidate recombinant vaccine has been developed. This vaccine - (RPV) was based on two protective proteins of $P$. aeruginosa: the outer membrane protein $\mathrm{F}(\mathrm{OprF})$ and the recombinant truncated form of the Exotoxin $A$ (toxoid) that were adsorbed on the aluminum hydroxide. The optimal immunization schedule for mice included two intraperitoneal administrations with a two-week interval. RPV promoted to increase survival rates in challenged immunized mice and stimulated humoral and innate immune responses. During preclinical studies, we confirmed the immunogenicity of the vaccine that had not pyrogenicity, acute and chronic toxicity, allergenicity and immunotoxicity.

Keywords: Pseudomonas aeruginosa, outer membrane protein $\mathrm{F}$ (OprF), toxoid, Pseudomonas Recombinant Vaccine (PRV)
\end{abstract}

\section{Introduction}

Pseudomonas aeruginosa is a conditionally pathogenic microorganism that causes purulent-inflammatory diseases of humans and animals. Usually Pseudomonas infection develops as a complication due to weakening of the immune system, which could be cause by various types of injuries and passed illnesses. Since $P$. aeruginosa is unpretentious to nutrients and is highly resistant to environmental factors and medicaments, including antibiotics, so this pathogen is widespread in the hospitals [1, 2]. According to World Health Organization, $P$. aeruginosa belongs to the first priority category among bacteria resistant to antibiotics [3]. Therefore, the development of vaccines is a promising direction for the prevention and the treatment of diseases caused by $P$. aeruginosa. An effective vaccine against $P$. aeruginosa should induce multiple mechanisms of immune response. Recent studies suggest that not only antibodies (that cause opsonophagocytosis and neutralize virulence factors of this bacterium), but also cellular factors, especially Th17 lymphocytes, play very important role in resistance against this pathogen [4]. 
For the immunological protection against $P$. aeruginosa, it is important to the presence of antibodies that bind with the surface antigens of the microorganism and neutralize bacterial toxins. Previously, we obtained the recombinant outer membrane protein $\mathrm{F}(\mathrm{OprF}$ ) [5] and the recombinant toxoid (non-toxic variant of exotoxin A without 106 C-terminal amino acid residues) of $P$. aeruginosa [5]. OprF is the major porin, which is obligatory for the successful survival of the microorganism and it has the conservative structure. Therefore, this protein is one of the most immunogenic surface antigens of $P$. aeruginosa [7]. Exotoxin A suppresses protein synthesis in the eukaryotic cells and is one of the main pathogenic factors $P$. aeruginosa that performs an important role in the destruction of the host tissues [8]. The recombinant OprF and the recombinant toxoid that were adsorbed on aluminum hydroxide adjuvant protected mice from experimental Pseudomonas infection, and their complex administration to animals induced an additive effect. The obtained results served as the basis for the design of the candidate recombinant vaccine, optimization of its composition and development of production technology [9].

The aim of our researching has been to obtain and immunobiological study of Recombinant Pseudomonas Vaccine (RPV), which based on the complex of recombinant OprF and toxoid. An important stage was development of the enzyme-linked assay for quantitative control of antigens the vaccine.

\section{Material and Methods}

\subsection{Preparation of RVP}

The preparations of the recombinant proteins and aluminum hydroxide were transferred into a sterile bottle and the volume was adjusted with sterile saline sodium chloride solution and during this, we used the following ratio: $0.5 \mathrm{ml}$ volume, $25 \mu \mathrm{g}$ the recombinant OprF, $50 \mu \mathrm{g}$ the recombinant toxoid and $225 \mu \mathrm{g}$ aluminum hydroxide. The adsorption of the antigens were performing in a refrigerator box with a temperature of $2-8{ }^{\circ} \mathrm{C}$ on a magnetic stirrer with a rotation speed of 60-100 rpm for 12 hours. The vaccine preparations were poured into sterile vials, sealed and stored at $2-8^{\circ} \mathrm{C}$.

\subsection{Enzyme-Linked Immunosorbent Assay (ELISA)}

The quantitative control of antigens in the vaccine was performed in two stages. At the first stage, $500 \mu \mathrm{g}$ solutions of peroxidase conjugated MkAb to OprF or toxoid 
antibodies were mixed in the test tubes with different amounts of RVP (from 0.5 to $10 \mu \mathrm{g} / \mathrm{ml}$ in terms of OprF or toxoid), and the samples were kept at a temperature of $18-25{ }^{\circ} \mathrm{C}$ for 40 minutes, stirring occasionally. The resulting complex of antibodies labeled with peroxidase with antigens absorbed on an aluminum hydroxide was separated by centrifugation. Antigen-unbound antibodies, labeled with HRP, remained in the supernatants were analyzed by enzyme immunoassay (second stage). Plates for ELISA prepared preliminarily: $100 \mu$ of recombinant proteins solutions in $0.05 \mathrm{M}$ Carbonate-Bicarbonate Buffer (CBB, Sigma), were added in 96-well plates (Corning, USA). Antigenes were being absorbed for $19-22$ hours at $4-8{ }^{\circ} \mathrm{C}$ and then the plates were washed 3 times with distilled water.

At the second stage $100 \mu$ of supernatants were added in the wells of the plate and incubated for 30 minutes in a shaker at a temperature of $37^{\circ} \mathrm{C}$, rotation speed of $500 \mathrm{rpm}$. After washing, peroxidase activity was detected using $33 \mathrm{mM}$ citrate buffer solution ( $\mathrm{pH}$ 4.0), containing $0.01 \%$ hydrogen peroxide and $0.5 \mathrm{mM} 3.3$ ', 5.5'tetramethylbenzidine. The reaction was stopped by the addition of $50 \mu / 2 \mathrm{~N}$ sulfuric acid, the optical density (OD) was measured in a two-wave mode at a wavelength of $450 \mathrm{~nm}$ and a reference wavelength of $680 \mathrm{~nm}$. A calibration graph of the dependence of optical density on the concentration of the recombinant toxoid or OprF in a standard batch was constructed. The recorded optical density was inversely proportional to the concentration of the recombinant toxoid or OprF in the analyzed samples of vaccine.

\subsection{Mice immunization and experimental infection}

The female BALB/c mice with 16-18 $\mathrm{g}$ weight were immunized. The vaccine preparations were injected intraperitoneally in the volume of $0.5 \mathrm{ml}$ twice with a two-week interval. Mice of the control group (mice of the same range) were injected with physiological sodium chloride solution. Two weeks after the last injection, the animals were challenged intraperitoneally with different doses $P$. aeruginosa strain PA-103. The immunized mice were challenged with the following doses: $10^{8}, 5.0 \rrbracket 10^{7}, 2.5 \rrbracket 10^{7}, 12.5 \rrbracket 10^{6}$ and $6.25 \otimes 10^{6}$ colony-forming units (CFU). Mice of the control group were challenged with the following doses: $5.0 \otimes 10^{7}, 2.5 \otimes 10^{7}, 12.5 \otimes 10^{6}, 6.25 \otimes 10^{6}$ and $3.125 \otimes 10^{6} \mathrm{CFU}$. Ten animals were in each group. The mortality of mice was registering during five days. $\operatorname{LD}_{50}$ was calculated by the formula: $\log _{L D 50}=\lg A-\lg 2 \times\left(B_{1} / C_{1}+B_{2} / C_{2}+B_{3} / C_{3}+B_{4} / C_{4}+\right.$ $\left.B_{5} / C_{5}-0.5\right)$. $A$ - the maximum infectious dose in the experiment; $B-$ the number of died animals in the group ; $C$ - the initial number of animals in the group (10 mice). 


\subsection{Measurement of cytokine levels in the serum}

We investigated the cytokine production in vivo in mice after single immunization with RVP. Blood was obtained from the immunized mice within 4, 8, and 24 hours and 14 days after immunization. The concentration of cytokines in serum of mice was determined using FlowCytomix Thl/Th2 Mouse 10 plex test system for the flow cytometry, according the manufacturer's instructions. The flow cytometer Cytomics FC500 was used. Concentrations of GM-CSF, IFN- $\gamma$, IL-1 1 , IL-2, IL- 4, IL-5, IL-6, IL-10, IL17 and TNF $\alpha$ was evaluated. The values of the concentration of cytokines in sera of the experimental and control animals were compared. The statistical reliability was evaluated by the Mann-Whitney criterion.

\section{Results and Discussion}

\subsection{Protection assay results}

Previously, we found out the optimal composition of the recombinant vaccine for the prevention of Pseudomonas infection: $25 \mu \mathrm{g}$ for the recombinant OprF protein and 50 $\mu \mathrm{g}$ for the recombinant toxoid that were absorbed on an aluminum hydroxide $(225 \mu \mathrm{g}$ in dose). For the aim of preclinical studies of recombinant vaccine, we obtained three lots of RVP were, that were examined to protect the immunized animals from intraperitoneal infection by $P$. aeruginosa strain PA-103 which is characterized by a high level of the exotoxin synthesis. Two weeks after the course of immunization by RVP, mice of the trial groups were injected with $P$. aeruginosa in different doses with a two-fold dilution step (from $6.25 \otimes 10^{6}$ to $10^{8} \mathrm{CFU}$ ). Mice of the control group were injected with slightly lower doses: from $3,125 \otimes 10^{6}$ to $5.0 \otimes 10^{7} \mathrm{CFU}$. $\mathrm{LD}_{50}$ value for the immunized mice were $6.6 \otimes 10^{7}, 6.16 \bowtie 10^{7}$ and $6.6 \otimes 10^{7} \mathrm{cfu}$ that was no less than three in comparison with $\mathrm{LD}_{50}$ value in the control group $\left(2.03 \otimes 10^{7} \mathrm{cfu}\right)$. Those results of survival rate after bacterial challenge test in immunized confirmed efficient of recombinant vaccine (Fig. 1).

1 - RVP, Lot 1; 2 - RVP, Lot 2; 3 - RVP, Lot 3; 4 - Control (intact mice). cfu - colony forming units. 


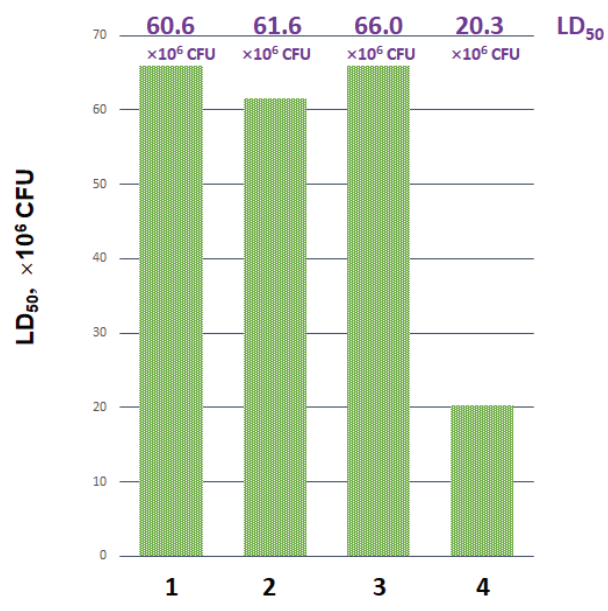

Figure 1: Protection by the experimental lots of RVP.

\subsection{Cytokine profile of peripheral blood of mice after immuniza- tion}

Significant changes in the concentration of cytokines in peripheral blood of mice were noted from 8 hours after immunization, and after 14 days (Fig. 2), no significant differences from the control were observed (excluding TNF- $\alpha$ ). The concentrations of all measured cytokines, including proinflammatory (as IL-1 $\alpha / \beta$, TNF- $\alpha$ ), Th1- (IL-2, IFN- $\gamma$, IL12) $[10]$ and Th2-stimulating (IL-4, IL-5, IL-6, IL-10, IL-13) [10, 11] were significantly increased. The concentration of IL-17 increased most strongly. This cytokine is especially important in immunity against $P$. aeruginosa [12]. Levels of IL-21 and IL-22, functionally similar and related to IL-17, [13] also increased. IL-21 has pleiotropic effects, including induction of differentiation along the Th17 pathway, activation of macrophages and NK cells IL$1 \beta$, together with TGF- $\beta$, TNF- $\alpha$-and IL- 6 , plays a key role in the induction of the Th17 response $[14,15]$. Thus, on the first day after immunization, the levels of proinflammatory cytokines, Th1, Th2, and Th17 cytokines increased, which indicates the activation of various mechanisms of the immune response. The most pronounced was the increase in the level of IL-17. The obtained results indicate the formation of Th17 response.

\subsection{Quantitative control of antigens in the vaccine}

Optimization of all stages of enzyme immunoassay was carried out. Assessing the quantitative content of recombinant proteins in the vaccine was performed using a standard batch of vaccine (RPV-1) containing toxoid - $100 \mu \mathrm{g} / \mathrm{ml}$ and OprF - $50 \mu \mathrm{g} / \mathrm{ml}$. A total of 3 vaccine batches were tested (one standard and two test series). The optimal 


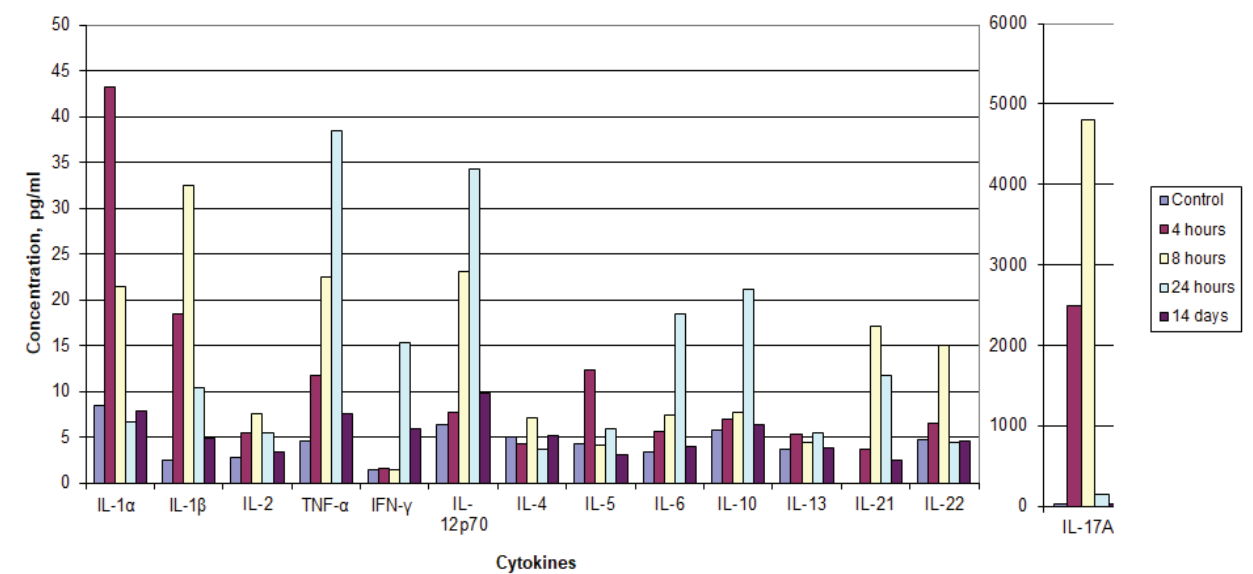

Figure 2: Changes in the concentration of cytokines $(\mathrm{pg} / \mathrm{ml})$ in the serum of immunized mice at different periods of observation.

TABLE 1: Results of determining toxoid and OprF in two batches of RVP

\begin{tabular}{llc|c} 
vaccine batches & $\begin{array}{l}\text { RVP -1 } \\
\text { batch) }\end{array}$ & (standard RVP -2 & RVP -3 \\
$\begin{array}{l}\text { Toxoid content in the } 100.0 \\
\text { batches, } \mu \mathrm{g} / \mathrm{ml}\end{array}$ & $104.9 \pm 2.4$ & $101.1 \pm 2.9$ \\
$\begin{array}{l}\text { OprF content in the } 50.0 \\
\text { batches, } \mu \mathrm{g} / \mathrm{ml}\end{array}$
\end{tabular}

concentration of toxoid or OprF immobilized on the surface of the plate wells was $2 \mu \mathrm{g}$ $/ \mathrm{ml}$ in coating buffer for both recombinant proteins, working dilutions of the MAb-HRP conjugates corresponded to 1:80.000. Calibration curves for quantitative assessment of recombinant proteins in the vaccine are presented in Figure 3.

Using the developed method, the studiy of the experimental series of the vaccine was carried out. In RVP-2 and RVP-3, $104.9 \pm 2,40$ and $101.10 \pm 2.90 \mu \mathrm{g} / \mathrm{ml}$ of toxoid was detected, respectively. In RVP-2 and RVP-3, $50.03 \pm 2.60$ and $45.40 \pm 3.20 \mu \mathrm{g} / \mathrm{ml}$ of OprF was detected, respectively (Tab. 1).

Thus, quantitative control of pilot vaccine batches showed that the content of OprF and toxoid in the vaccine varied slightly between batches (less than $15 \%$ ).

\subsection{Safety assessment of RVP}

During of preclinical studies of three experimental lots of RPV, we confirmed to assessment of sterility, authenticity and the absence of DNA contamination of the producer strains. Chromogenic LAL assay shown that the amount of endotoxin in the experimental series of the vaccine not exceed the threshold value. The apyrogenicity of RVP was reconfirmed in experiments on animals: the vaccine did not cause temperature reactions 

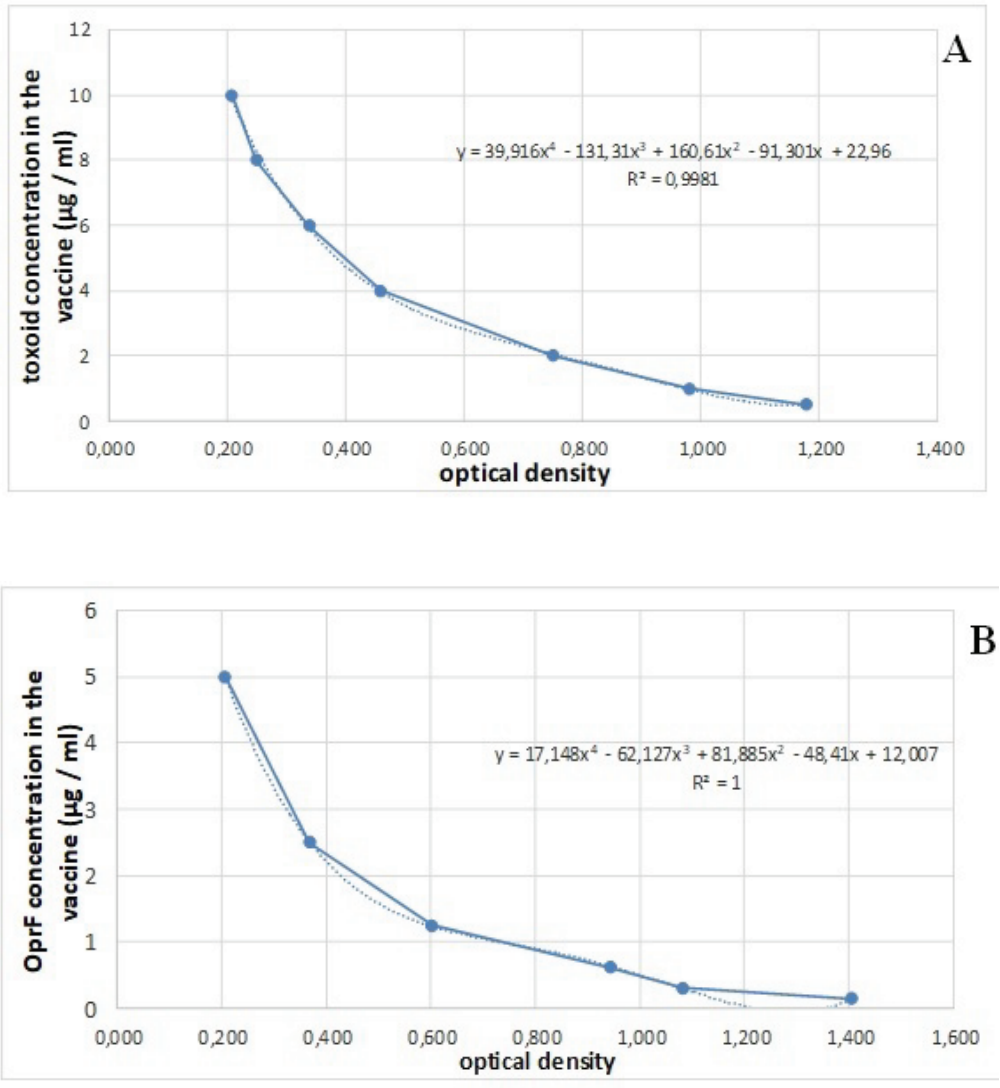

Figure 3: Calibration graphs for the quantitative determination of toxoid $(A)$ and OprF (B) in the vaccine $(\mu \mathrm{g} / \mathrm{ml})$.

when it was administered to rabbits. In experiments on mice and guinea pigs, the absence of the abnormal toxicity of RVP was shown. The study of the allergenic properties was carried out by the subcutaneous administration of the vaccine to guinea pigs. At result, the insignificant allergic reactions were revealed when we injected the vaccine to animals at a dose tenfold higher than the intended for humans dose. In response to the administration of the recombinant vaccine to mice, there were no the delayed-type hypersensitivity reactions.

In the study of acute and chronic toxicity of the vaccine, the animals of the two species were injected with one and ten human doses. The recombinant vaccine had not the acute toxicity for mice and guinea pigs that was shown on the 7th and 15th days after one immunization. When assessing the chronic toxicity, the vaccine was administered daily for 10 days to rats and guinea pigs, after that we also did not observe any undesirable synonyms. Analysis of the weight of animals, the hematological parameters (general and biochemical blood tests), morphological and histological parameters did not reveal the significant pathological changes in the experimental animals. 


\section{Conclusion}

Our studies show that Pseudomonas Recombinant Vaccine (PRV) induce a protective immunity that provide to increase the survival rate of immunized mice from $P$. aeruginosa infection. RVP induce a secretion of wide spectrum of cytokines in vivo. These cytokines can induce differentiation of T-helpers and its polarization, include into Th1, Th2 and most important Th17 subtype. During preclinical studies, we confirmed the immunogenicity of the vaccine that had not pyrogenicity, acute and chronic toxicity, allergenicity and immunotoxicity. Therefore PRV that can be considered as a new protective recombinant vaccine for $P$. aeruginosa infections.

\section{References}

[1] Grimwood, K., et al. (2015) Vaccination against respiratory Pseudomonas aeruginosa infections. Hum. Vaccin. Immunothe, vol. 11, issue 1, pp. 14-20. https://doi.org/10.4161/hv.34296.

[2] Lazareva, A.V., et al. (2015) Pseudomonas aeruginosa: Pathogenicity, Pathogenesis and Diseases. Klinicheskaya mikrobiologiya i antimikrobnaya khimioterapiya, vol. 17, issue 3 , pp. 170-186.

[3] World Health Organization. (2017) WHO publishes list of bacteria for which new antibiotics are urgently needed. Geneva: World Health Organization.

[4] Merakou, C., et al. (2018) Progress Toward the Elusive Pseudomonas aeruginosa Vaccine. Surg Infect (Larchmt), vol. 19, issue 8, pp. 757-768. https://doi.org/10.1089/sur.2018.233

[5] Kaloshin A.A., et al. (2011) Obtaining recombinant forms of the outer membrane protein $\mathrm{F}$ of Pseudomonas aeruginosa and assessment of their immunogenic properties. Applied Biochemistry and Microbiology, vol. 47, issue 8, pp. 780-788. https://doi.org/10.1134/S0003683811080060

[6] Kaloshin A.A., et al. (2013) Preparation of Recombinant Atoxic Form of Exotoxin A from Pseudomonas aeruginosa. Bulletin of Experimental Biology and Medicine, vol. 154, issue 3, pp. 346-350. https://doi.org/10.1007/s10517-013-1947-1

[7] Gilleland H.E. Jr, et al. (1984) Use of a purified outer membrane protein F (porin) preparation of Pseudomonas aeruginosa as a protective vaccine in mice. Infect Immun, vol. 44, issue 1, pp. 49-54.

[8] Michalska, M. and Wolf, P. (2015) Pseudomonas Exotoxin A: optimized by evolution for effective killing. Front Microbiol, vol. 6, pp. 963. 
https://doi.org/10.3389/fmicb.2015.00963

[9] Kaloshin A.A., et al. (2016) Assessment of Protective Properties of the Recombinant Complex of the Outer Membrane Protein F and the Toxoid of Pseudomonas aeruginosa. Vestnik Rossiiskoi Akademii Meditsinskikh Nauk, vol. 71, issue 1, pp. 1-5. https://doi.org/10.15690/vramn584

[10] Delves P.J., et al. (2017) Roitt's essential immunology, 13th edition. Publisher: Chichester, West Sussex: John Wiley \& Sons, Ltd.

[11] Caucheteux SM., et al. (2016) IL-1 $\beta$ enhances inflammatory TH2 differentiation. J Allergy Clin Immunol, vol. 138, issue 3, pp. 898-901. https://doi.org/10.1016/j.jaci.2016.02.033

[12] Liu J., et al. (2011) Early production of IL-17 protects against acute pulmonary Pseudomonas aeruginosa infection in mice. FEMS Immunol Med Microbiol, vol. 61, issue 2, pp. 179-88. https://doi.org/10.1111/j.1574-695X.2010.00764.x

[13] Bayes H.K., et al. (2014) T helper cell subsets specific for Pseudomonas aeruginosa in healthy individuals and patients with cystic fibrosis. PLoS One, vol. 9, issue 2, pp. e90263. https://doi.org/10.1371/journal.pone.0090263

[14] Di Paolo N.C. and Shayakhmetov D.M. (2016) Interleukin $1 \alpha$ and the inflammatory process. Nat Immunol, vol. 17, issue 8, pp. 906-913. https://doi.org/10.1038/ni.3503.

[15] Santarlasci V., et al. IL-1 and T Helper Immune Responses. Front Immunol, vol. 4, pp. 182. https://doi.org/10.3389/fimmu.2013.00182 